\title{
LAMA RAWATAN DAN DIRECT COST PASIEN KAKI DIABETIK TERAMPUTASIDI RS DR. ZAINOEL ABIDIN BANDA ACEH : PRE- ELIMINARY STUDY
}

\author{
Hendra Zufry ${ }^{1}$ \\ ${ }^{1}$ Divisi Endokrinologi, Metabolik dan Diabetes - Pusat Pelayanan Tiroid Terpadu \\ Bagian Ilmu Penyakit Dalam Fakultas Kedokteran Universitas Syiah Kuala \\ RSUD dr. Zainal Abidin Banda Aceh \\ *Corresponding Author : hendra.zufry@gmail.com
}

\begin{abstract}
Abstrak
Kaki Diabetik adalah salah satu komplikasi Diabetes Mellitus (DM) yang sangat umum terjadi dan dapat menyebabkan infeksi, amputasi bahkan kematian. Amputasi sendiri menghabiskan banyak kerugian sehingga menjadi beban dalam pelayanan kesehatan. TujuanPenelitian ini bertujuan melihat gambaran lama rawatan dan direct cost pasien kaki diabetik teramputasi di RS Dr.Zainoel Abidin Banda Aceh.Metode Penelitian :Penelitian ini merupakan suatu pre-eliminary study yang bersifat deskriptif. Data pasien diambil dari rekam medis pasien. Setiap pasien akan dinilai tipe luka, masa rawatan dan biaya yang dihabiskan selama rawatan.

Hasil : Dari 37 pasien yang menjalani amputasi, didapatkan rerata rawatan selama 15 hari dengan rerata biaya yang dihabiskan sebesar 45,5 juta rupiah. Dari keseluruhan, 5 orang (14\%) memiliki tipe luka neuropati, 20 orang (54\%) tipe vaskulopati dan 12 orang (32\%) tipe infeksi. Dari 5 orang pasien dengan luka neuropati, lama rawatan adalah $11 \pm 7,19$ hari dan rerata biaya yang dihabiskan sebesar 42,3 juta rupiah . Pada 20 pasien dluka vaskulopati, lama rawatan adalah $14 \pm 6,95$ hari serta rerata biaya yang dikeluarkan adalah 41,1 juta rupiah. Sedangkan 12 pasien luka infeksi, didapatkan rerata lama rawatan adalah $17 \pm 8,13$ hari dengan rerata biaya sebesar 54 juta rupiah Kesimpulan : Hasil penelitian ini memperlihatkan bahwa rerata masa rawatan dan rerata biaya rawatan pasien ulkus diabetikum yang menjalani amputasi di RS dr.Zainoel Abidin pada tahun 2017 cukup tinggi. Akan tetapi untuk masing - masing tipe luka, lama masa rawatan dan biaya yang dikeluarkan tidak terlalu jauh berbeda.
\end{abstract}

Kata Kunci: Kaki diabetik; lama rawatan; direct cost 


\title{
The duration of care and direct cost of amputate diabetic foot patient in RS Dr. Zainoel Abidin Banda Aceh : pre-eliminary study
}

\begin{abstract}
Diabetic foot is the most common complications of Diabetes Mellitus (DM) and may lead to infection, amputation, death and it becomes a burden in health services. ObjectiveTo observe the duration of care and direct cost of amputate diabetic leg patients in Dr.Zainoel Abidin Hospital Banda Aceh. Method : This research is a descriptive pre-eliminary study. Patient data was taken from the patient's medical records. Each patient will be assessed for the type of injury, lifetime and expenses incurred during the treatment. Result : Thirty seven patients who underwent amputation and complete data with the average treatment was obtained for 15 days with average cost of 45.5 million rupiah. Five patients $(14 \%)$ had neuropathic wound type, 20 people $(54 \%)$ of vasculopathy type and 12 people $(32 \%)$ of infection type. Five patients with neuropathic injury, the duration of treatment was $11 \pm 7.19$ days and the mean cost was 42.3 million rupiah. In 20 patients with vasculopathy, treatment duration was $14 \pm$ 6.95 days and mean cost was 41.1 million rupiah. While 12 patients categorized in wound infection, obtained the average length of stay $17 \pm 8.13$ days with the average cost of 54 million rupiah Conclusion : The results of this study show that the average of treatment and average cost of treatment of diabetic ulcer patients who underwent amputation at RS dr.Zainoel Abidin in 2017 is quite high. However, for each type of wound, the duration of care and expenses are not too different.
\end{abstract}

Key words: Diabetic foot; duration of care; direct cost 


\section{Pendahuluan}

Diabetes Mellitus (DM) adalah salah satu masalah utama dalam sistem kesehatan dan merupakan ancaman kesehatan pada masyarakat global. Penyakit ini telah meningkat secara dramatis selama 2 dekade terakhir. ${ }^{1,2}$ Menurut penelitian epidemiologi, jumlah pasien dengan DM meningkat dari sekitar 30 juta kasus pada tahun 1985, 177 juta di tahun 2000, 285 juta di tahun 2010, dan diperkirakan jika situasinya terus berlanjut, lebih dari 360 juta orang pada tahun 2030 akan menderita DM. ${ }^{3,4}$ Pasien dengan DM rentan terhadap banyak komplikasi seperti Diabetic Foot Ulcer (DFU) atau kaki diabetik. Kaki diabetik adalah komplikasi DM yang secara patofosiologi dapat terjadi akibat keadaan neuropati, vasculopaty ataupun infeksi. Kaki diabetik telah menunjukkan angka yang semakin meningkat dari dekade sebelumnya ${ }^{5,6,7}$ Secara total, diperkirakan $15 \%$ pasien diabetes akan menderita kaki diabetik selama seumur hidup mereka. ${ }^{8}$

Meski angka yang akurat dalam mendapatkan prevalensi kaki diabetik sulit, komplikasi ini berkisar antara 4\% -27\% . Sampai saat ini, kaki diabetik dianggap sebagai sumber utama morbiditas dan penyebab utama rawat inap pada pasien dengan diabetes. Diperkirakan kirakira 20\% penerimaan rumah sakit pada pasien DM adalah akibat kaki diabetik. Kaki diabetik sendiri bisa menyebabkan infeksi, gangren, amputasi, dan bahkan kematian jika fasilitas perawatan yang diperlukan tidak tersedia. Di sisi lain, disaat sarana perawatan untuk kaki diabetik disediakan, maka akan beresiko untuk terjadi peningkatan rawatan yang akhirnya meningkatkan resiko untuk amputasi. ${ }^{9}$

Secara keseluruhan, tarif amputasi anggota badan bagian bawah pada pasien DM adalah 15 kali lebih tinggi dibanding pasien tanpa diabetes Diperkirakan juga sekitar 50\% $70 \%$ dari semua amputasi anggota badan bagian bawah adalah karena kaki diabetik. ${ }^{8,9}$. Selanjutnya, kaki diabetik juga menjadi penyebab terhadap perubahan emosi dan kesulitan fisik serta produktivitas dan kerugian keuangan yang menurunkan kualitas hidup. Literatur sebelumnya menunjukkan bahwa penyembuhan biaya ulkus tunggal sekitar \$ 17500 ( Dolar Amerika Serikat). Dalam kasus di mana diperlukan amputasi ekstremitas bawah, perawatan kesehatan bahkan lebih mahal bisa mencapai \$30000-33500 (Dolar amerika Serikat). Biaya ini tidak mewakili total beban ekonomi, karena indirect cost terkait dengan kerugian produktivitas, upaya preventif, rehabilitasi, dan perawatan di rumah harus dipertimbangkan. Bila semua ini dipertimbangkan, 7\% -20\% dari total pengeluaran untuk diabetes di Amerika Utara dan Eropa mungkin disebabkan oleh kaki diabetik. 
Biaya rawatan sendiri terdiri dari direct cost, indirect cost dan intangible cost. Dalam Cost of Illness (COI) study, ketiga komponen biaya tersebut harus diperhitungkan. Direct Cost merupakan biaya dari semua jenis sumber daya yang digunakan untuk mengobati penyakit. Direct cost termasuk biaya rawat inap rumah sakit, biaya dokter, biaya rawat jalan, dokter rawat inap, kunjungan ke unit gawat darurat, dan unit kesehatan lainnya seperti perawatan profesional, tes diagnostik, resep obat dan pengobatan medis. Indirect cost mencakup kerugian produktivitas yang terkait dengan morbiditas dan mortalitas. Kehilangan produktivitas meliputi penurunan produktivitas terdahulu ( selama rawatan) atau penurunan produktivitas bagi mereka yang terus bekerja meski menderita diabetes. Indirect Cost bagi sebagian Cost of Illness study merupakan bagian biaya yang paling besar. Intangible cost mengacu pada nyeri psikologis pasien, ketidak nyamanan, kecemasan dan kesusahan terkait penyakit tersebut . ${ }^{13,23}$

Banyak penelitian yang melihat besarnya kerugian yang ditimbulkan oleh komplikasi akibat DM terutama kaki diabetik, terutama pada negara - negara berkembang. ${ }^{18,20,21,22}$ Beberapa Rumah sakit di Indonesia juga sudah melakukan penelitian direct cost yang sama. Penelitian ini bertujuan untuk melihat lama rawatan dan besarnya direct cost pada pasien kaki diabetik yang menjalani amputasi di RS dr. Zainoel Abidin Banda Aceh pada tahun 2017.

\section{Metode Penelitian}

\section{Rancangan penelitian}

Penelitian ini merupakan Real World Evidence Study yang bersifat deskriptif dan berbasis rekam medis. Penelitian ini melihat gambaran masa rawatan dan direct cost pasien kaki diabetik yang menjalani amputasi di RS dr.Zainoel Abidin, Banda Aceh pada tahun 2017. Kami mencatat jumlah awal sebanyak 65 pasien dengan kaki diabetik yang mengalami operasi amputasi pada tahun 2017. 28 orang pasien kami ekslusikan karena data yang tidak lengkap. Pada penelitian ini kami juga memisahkan pasien berdasarkan tipe luka yang dialami berdasarkan patofisiologinya. Kami menilai lamanya masa rawatan dan biaya yang dihabiskan selama rawatan. Baik secara keseluruhan atau pada masing - masing tipe luka.

\section{Waktu dan tempat penelitian}

Pengambilan sampel dilakukan di instalasi Rekam medis RS dr. Zainoel Abidin, Banda Aceh mulai tanggal 1 februari 2017 sampai dengan 12 Februari 2018

\section{Populasi dan sampel penelitian}

Populasi pada penelitian ini adalah seluruh pasien dengan kaki diabetik yang menjalani amputasi pada tahun 2017. Sampel penelitian adalah pasien dengan kaki diabetik yang menjalani amputasi pada tahun 2017 dengan data rekam medik yang lengkap 


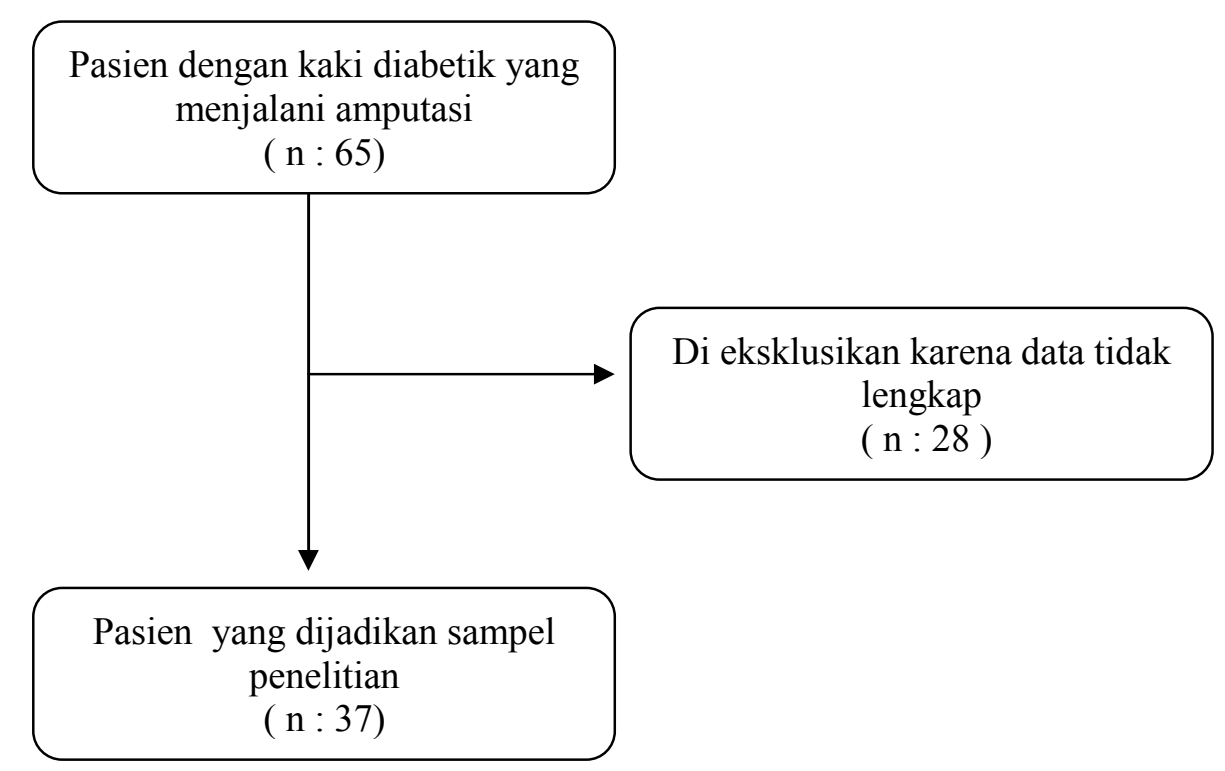

\section{Gambar 1. Alur pengambilan sampel}

\section{Definisi operasional}

Dalam penelitian ini, kami mengambil sampel pasien DM dengan komplikasi kaki diabetik. Dalam hal ini kaki diabetik adalah komplikasi pada kaki yang dialami pasien DM. Kami membagi jenis kaki diabetik berdasarkan patofisiologinya yaitu neuropati, vasculopati dan infeksi. Masa rawatan adalah jumlah hari dimana pasien dirawat saat dilakukan amputasi. Jumlah hari dihitung dari pasien masuk sampai meninggalkan rumah sakit. Sementara direct cost adalah semua biaya yang dikeluarkan selama rawatan yang berhubungan dengan pelayanan kesehatan.

\section{Analisa Data Penelitian}

Data yang didapat dari rekam medis pasien lalu dikumpulkan, ditabulasi, dan dikalkulasi rata - rata hari rawatan dan biaya rawatannya baik secara keseluruhan ataupun pada masing - masing tipe luka. Analisa statistik dilakukan secara univariat dengan menampilkan data dalam bentuk tabel. Data deskriptif rerata lama rawatan dan besarnya biaya selama rawatan akan disajikan dalam tabel dan grafik.

\section{Hasil Penelitian}

Telah dilakukan suatu pre-eliminary study pada pasien kaki diabetik yang menjalani operasi amputasi pada tahun 2017. Berdasarkan jenis kelamin (22 laki-laki, 15 perempuan) dengan usia $57 \pm 9,4$ tahun dengan rerata masa rawatan $15 \pm 7,5$ hari, rerata lama luka $185 \pm$ 103 hari, rerata lama diabetes $8 \pm 4,1$ tahun, dan rerata waktu menunggu amputasi selama 
masa rawatan $180 \pm 102,4$ jam serta outcome $35(95 \%)$ pasien perbaikan dan $2(5 \%)$ orang meninggal.

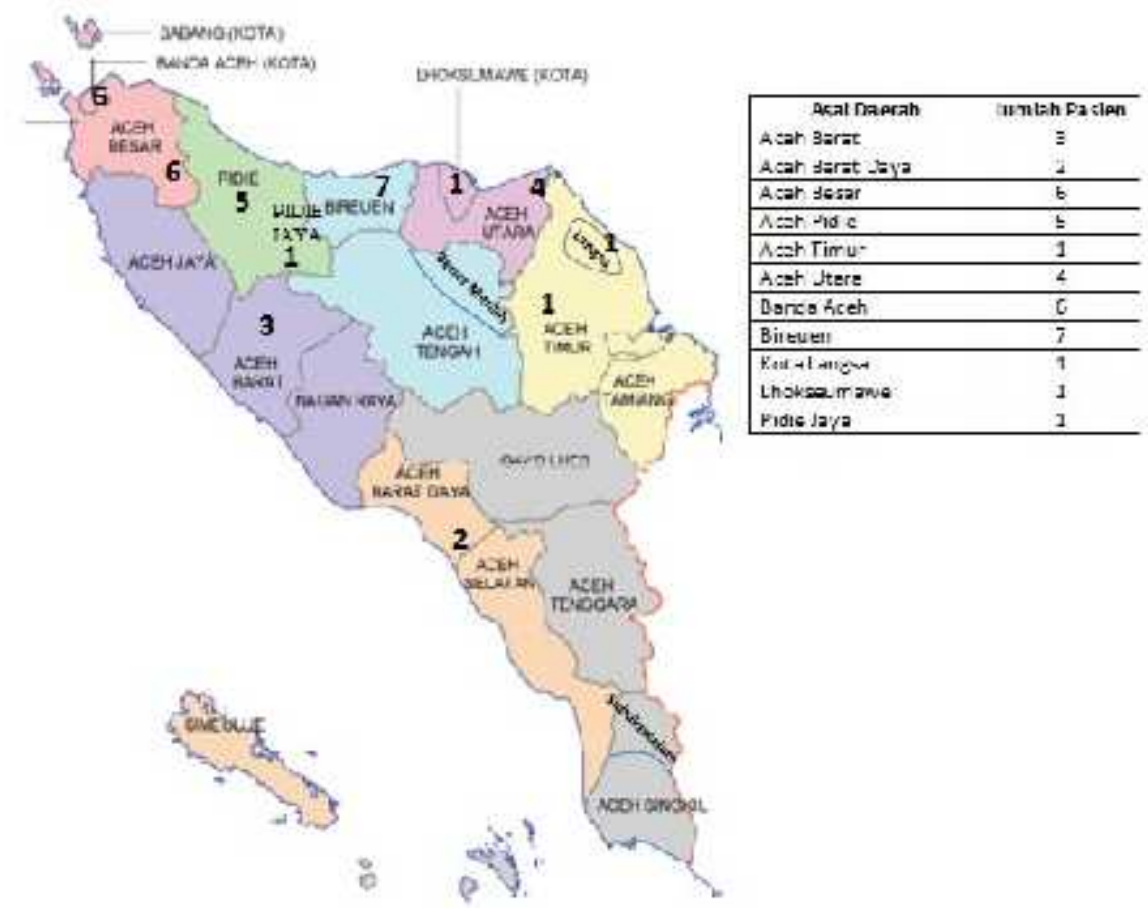

Gambar 1. Data demografi pasien yang menjalani amputasi di rumah sakit dr. Zainoel Abidin Banda Aceh tahun 2017.

Tabel 1. Karakteristik pasien kaki diabetik yang menjalani amputasi di Rumah Sakit dr. Zainoel Abidin Banda Aceh Tahun 2017

\begin{tabular}{ll}
\hline Variabel & Data keseluruhan $(\mathbf{n}=\mathbf{3 7})$ \\
\hline Jenis Kelamin & \\
$\quad$ Laki-Laki & $22(59 \%)$ \\
$\quad$ Perempuan & $15(41 \%)$ \\
Umur (tahun) & $\mathbf{5 6 , 9} \pm \mathbf{9 , 4}$ \\
Lama rawatan (hari) & $\mathbf{1 4 , 8} \pm \mathbf{7 , 5}$ \\
Lama menderita luka (hari) & $\mathbf{1 0 2 , 9} \pm \mathbf{1 8 5}$ \\
Lama menderita DM (Tahun) & $\mathbf{7 , 7} \pm \mathbf{4 , 1}$ \\
Waktu menunggu amputasi selama rawatan (jam) & \\
Data Laboratorium & $\mathbf{1 8 0} \pm \mathbf{1 0 2 , 4}$ \\
$\quad$ Hemoglobin $(\mathrm{gr} \%)$ & \\
$\quad$ Leukosit $x 10^{3} / \mu \mathrm{L}$ & $9,01 \pm 1,72$ \\
\hline
\end{tabular}




\begin{tabular}{cl}
\hline Trombosit $10^{3} / \mu \mathrm{L}$ & $20,1 \pm 10,2$ \\
Status Saat Keluar dari RS & $429,2 \pm 132,4$ \\
Perbaikan (Hidup) & $35(95 \%)$ \\
Perburukan (Meninggal) & $2(5 \%)$ \\
\hline
\end{tabular}

Dari 37 pasien ulkus diabetikum yang mengalami amputasi didapatkan rerata rawatan selama 15 hari dengan rerata biaya yang dihabiskan sebesar 45,5 juta rupiah. Kami membagi pasien kaki diabetik menjadi tiga tipe luka berdasarkan patofisiologinya yaitu neuropati , vasculopati dan infeksi

Tabel 2. Tabel distribusi pasien berdasarkan tipe luka

\begin{tabular}{ccc}
\hline Tipe Luka & Frekuensi & Persen \\
\hline Neuropati & 5 & 14 \\
Vasculopati & 20 & 54 \\
Infeksi & 12 & 32 \\
\hline Jumlah & 37 & $100 \%$ \\
\hline
\end{tabular}

Tabel 2 menunjukkan bahwa dari 37 pasien yang menjalani amputasi, 5 orang (14\%) memiliki tipe luka neuropati, 20 orang ( $54 \%$ ) tipe vaskulopati dan 12 orang (32\%) dengan tipe infeksi.

Tabel 3. Tabel rerata lama rawatan berdasarkan tipe luka

\begin{tabular}{ccc}
\hline Tipe Luka & $\begin{array}{c}\text { Rerata Lama } \\
\text { Rawatan (hari) }\end{array}$ & Standar Deviasi \\
\hline Neuropati & 11 & 7,19 \\
Vasculopati & 14 & 6,95 \\
Infeksi & 17 & 8,13 \\
\hline
\end{tabular}

Dari tabel diatas (tabel 3) terlihat rerata lama rawatan untuk luka tipe neuropati adalah 11 hari ( SD : $\pm 7,19$ ). Rerata lama rawatan luka tipe vasculopati adalah 14 hari ( SD : \pm $6,95)$ dan rerata rawatan untuk luka infeksi adalah 17 hari (SD : $\pm 8,13$ ). Gambaran rerata juga kami tampilkan dalam bentuk grafik rerata lama rawatan ( gambar 2) 


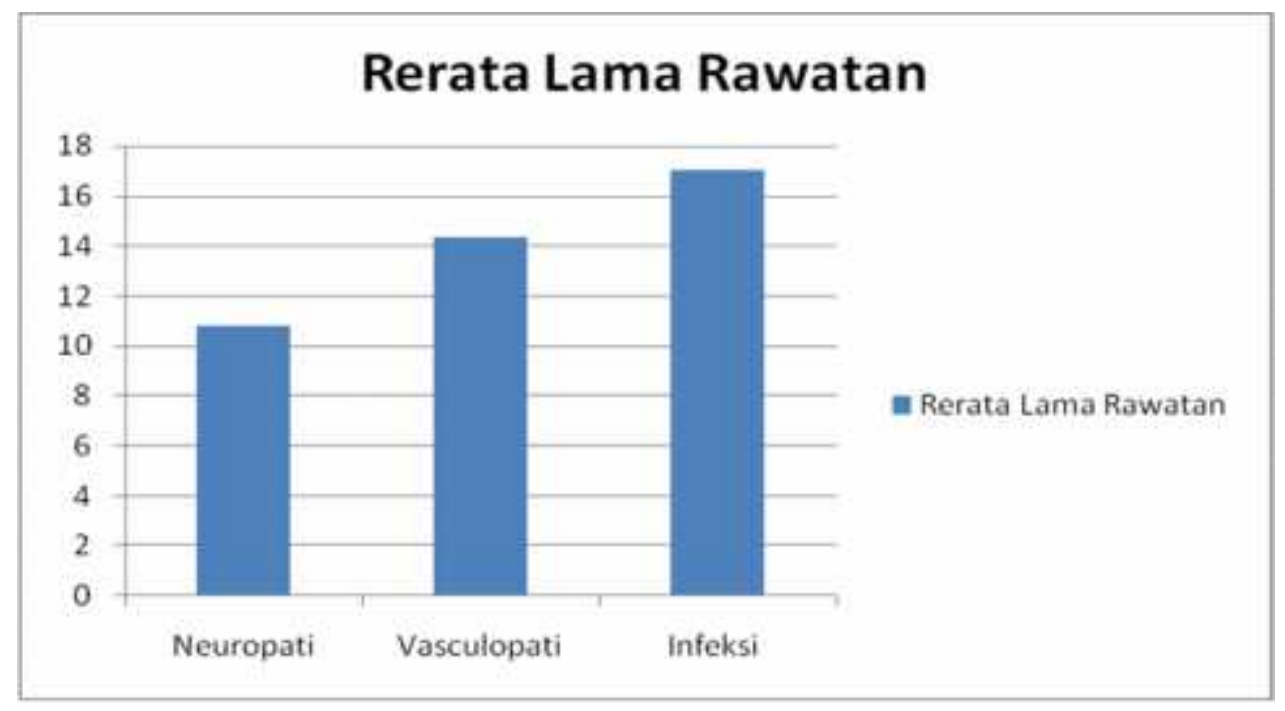

Gambar 2. grafik rerata lama rawatan

Sementara untuk gambaran rerata direct cost pasien amputasi untuk tiap tipe luka kami sajikan dalam tabel 4

Tabel 4. Rerata direct cost pasien berdasarkan tipe luka

\begin{tabular}{ccc}
\hline Tipe Luka & $\begin{array}{c}\text { Rerata Direct Cost } \\
\text { (juta rupiah ) }\end{array}$ & Standar Deviasi \\
\hline Neuropati & 42,3 & 25,3 \\
Vasculopati & 41,1 & 11,6 \\
Infeksi & 54 & 25,2 \\
\hline
\end{tabular}

Dari ketiga tipe luka terlihat bahwa luka neuropati memiliki rerata direct cost 42,3 juta rupiah ( $\mathrm{SD}: \pm 25,3$ ). Luka tipe vasculopati memiliki direct cost 41,1 juta (SD : $\pm 11,6$ ) dan luka infeksi memiliki direct cost yang sedikit lebih tinggi yaitu 54 juta rupiah ( SD : $\pm 25,2$ ) - Gambaran rerata direct cost ini juga kami tampilkan dalam bentuk grafik rerata biaya rawatan (gambar 3). 


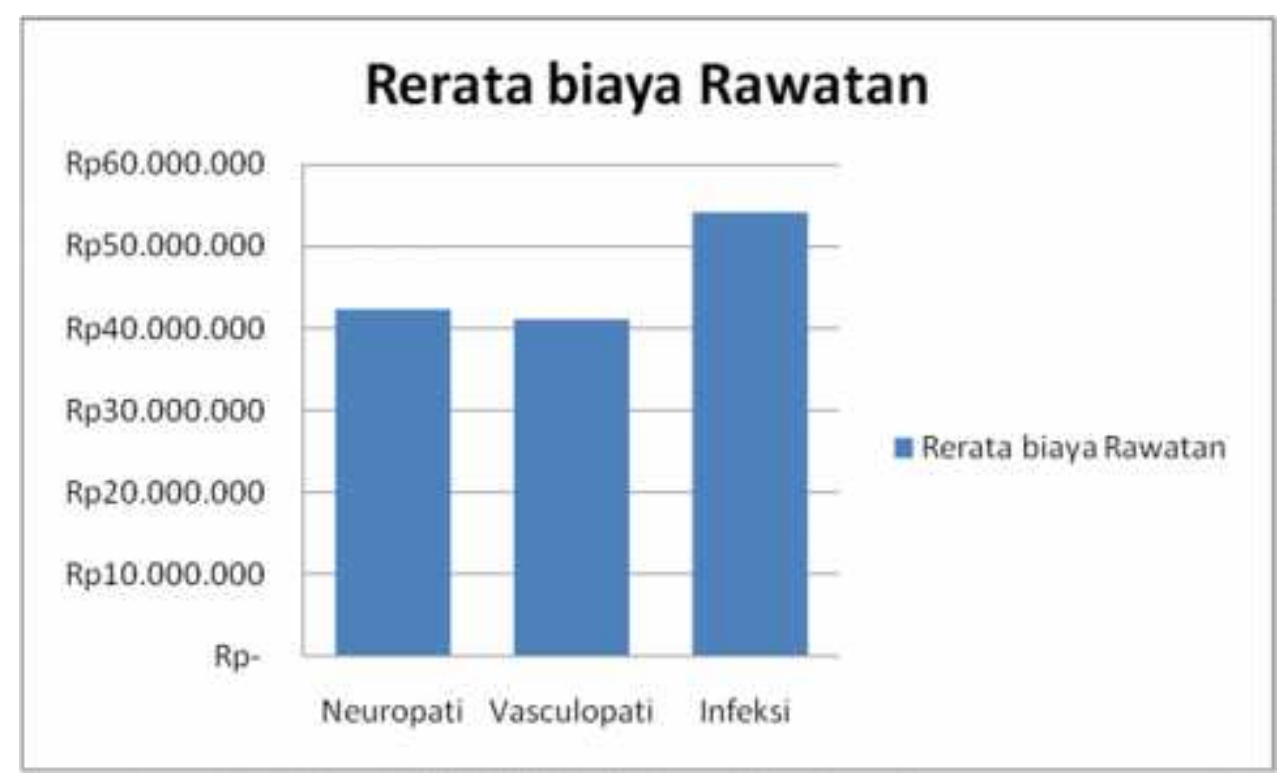

\section{Gambar 3. Grafik rerata biaya rawatan pada pasien amputasi}

\section{Pembahasan}

Dalam penelitian ini, kami ingin melihat gambaran lama rawatan dan biaya pengobatan pasien diabetes dengan ulkus kaki yang menjalani amputasi. Seperti yang kita ketahui bahwa penyakit diabetes mellitus merupakan penyakit yang memiliki komplikasi yang cukup banyak. Komplikasi yang banyak ini di beberapa negara bisa menjadi beban kesehatan. Banyak penelitian yang dilakukan terutama pada negara berkembang untuk menilai beban biaya kesehatan . Keskek SO, dkk melakukan penelitian untuk melihat biaya rawatan yang ditimbulkan pasien dengan kaki diabetik. Mereka menemukan bahwa biaya yang di keluarkan untuk rawatan pasien dengan kaki diabetikum cukup tinggi dan menjadi beban pada pelayanan kesehatan, terutama untuk pasien yang menjalani operasi. ${ }^{18}$

Penelitian ini menunjukkan rerata lama rawatan dan direct cost pasien kaki diabetikum dengan amputasi adalah 15 hari dan 45,5 juta rupiah. Harga ini tergolong cukup tinggi. Penelitian - penelitian sebelumnya juga menunjukkan bahwa biaya pengobatan sebagian besar disebabkan oleh komplikasi diabetes melitus. ${ }^{17,18,19,20}$ Dalam penelitian oleh Al-Maskari dkk, direct cost untuk diabetes di Uni Emirat Arab dilaporkan 1605 USD (20,8 juta rupiah). Biaya ini meningkat 6,4 kali untuk pasien dengan komplikasi makrovaskular. Kim dkk juga melaporkan bahwa direct cost tahunan pasien dengan komplikasi makrovaskular, mikrovaskular dan keduanya masing - masing 7, 1,5 dan 2,0 kali lebih tinggi dari pada pasien tanpa komplikasi. ${ }^{17}$ Biaya pengobatan yang tinggi disebabkan oleh intervensi selain perawatan medis. ${ }^{17,23}$ 
Rerata lama rawatan pada tiap tipe luka tidak jauh berbeda. Untuk gambaran direct cost terlihat tipe luka infeksi sedikit lebih tinggi walaupun jumlah pasiennya lebih sedikit. Kim TG dkk dalam penelitiannya mendapatkan bahwa banyak faktor yang mempengaruhi lama rawatan pasien dengan kaki diabetik. Antara lain reaksi inflamasi, kadar gula yang tidak terkontrol, Body Mass Index dan adanya penyakit kardiovascular. Akan tetapi penelitian tersebut hanya menilai kaki diabetik infeksi tanpa tindakan amputasi. ${ }^{17,20,23}$

Keskek dkk dalam penelitiannya juga mengungkapkan bahwa banyak hal lain yang membuat panjangnya masa rawatan pasien kaki diabetik termasuk penyembuhan luka dan adanya komplikasi lain yang berkembang. Namun untuk besarnya biaya, mereka menemukan bahwa semua tipe luka termasuk tipe neuropati dan vasculopati juga memiliki direct cost yang tinggi akibat keadaan atherosclerosis atau neuropati yang berperan dalam penyembuhan luka. ${ }^{18}$

Penelitian ini merupakan Real Word Study yang berbasis rekam medik dan bersifat deskriptif. Semua data diambil berdasarkan keadaan sebenarnya. Kekurangan dari penelitian ini antara lain adalah karena hanya melihat gambaran masa rawatan dan besarnya direct cost secara umum, kami tidak melihat faktor - faktor yang mempengaruhi seperti penggunaan jenis antibiotik, adanya penyakit penyerta, parameter laboratorium atau komplikasi lain yang timbul setelah dilakukan amputasi. Jumlah yang kami jadikan sampel juga tidak terlalu banyak dari keseluruhaan populasi karena ada beberapa data yang tidak lengkap. Oleh karena itu sangat dibutuhkan penelitian lanjutan lain yang lebih menyeluruh untuk mendapatkan hasil yang lebih baik.

\section{Kesimpulan}

Dari penelitian ini terlihat bahwa lama rawatan dan direct cost pada pasien kaki diabetik yang menjalani amputasi di RS dr. Zainoel Abidin, Banda Aceh tahun 2017 cukup tinggi. Sememtara untuk masing - masing tipe luka , lama rawatan dan besarnya direct cost tidak terlalu jauh berbeda. Diperlukan penelitian lanjutan yang lebih lengkap untuk hasil yang lebih baik.

\section{Daftar Pustaka}

1. Shahbazian H, Yazdanpanah L, Latifi SM. Risk assessment of patients with diabetes for foot ulcers according to riskclassification consensus of International Working Group on Diabetic Foot (IWGDF). Pak J Med Sci 2013; 29: 730-734

2. Ramachandran A, Snehalatha C, Shetty AS, Nanditha A. Trends in prevalence of diabetes in Asian countries. World J Diabetes 2012; 3: 110-117 [PMID: 22737281 DOI: $10.4239 /$ wjd. v3.i6.110] 
3. Shaw JE, Sicree RA, Zimmet PZ. Global estimates of the prevalence of diabetes for 2010 and 2030. Diabetes Res Clin Pract 2010; 87: 4-14 [PMID: 19896746 DOI: 10.1016/ j.diabres.2009.10.007]

4. Whiting DR, Guariguata L, Weil C, Shaw J. IDF diabetes atlas: global estimates of the prevalence of diabetes for 2011 and 2030. Diabetes Res Clin Pract 2011; 94: 311-321 [PMID: 22079683 DOI: 10.1016/j.diabres.2011.10.029]

5. Aalaa M, Malazy OT, Sanjari M, Peimani M, Mohajeri- Tehrani M. Nurses' role in diabetic foot prevention and care; a review. J Diabetes Metab Disord 2012; 11: 24

6. Alavi A, Sibbald RG, Mayer D, Goodman L, Botros M, Armstrong DG, Woo K, Boeni T, Ayello EA, Kirsner RS. Diabetic foot ulcers: Part II. Management. J Am Acad Dermatol 2014; 70: 21.

7. Cavanagh PR, Lipsky BA, Bradbury AW, Botek G. Treatment for diabetic foot ulcers. Lancet 2005; 366: 1725-1735

8. Leone S, Pascale R, Vitale M, Esposito S. [Epidemiology of diabetic foot]. Infez Med 2012; 20 Suppl 1: 8-13

9. Bakri FG, Allan AH, Khader YS, Younes NA, Ajlouni KM. Prevalence of Diabetic Foot Ulcer and its Associated Risk Factors among Diabetic Patients in Jordan. $J$ Med $J$ 2012; 46:118-125

10. Vileikyte L. Diabetic foot ulcers: a quality of life issue. Diabetes Metab Res Rev 2001; 17: 246-249 [PMID: 11544609

11. Ragnarson Tennvall G, Apelqvist J. Health-economic consequences of diabetic foot lesions. Clin Infect Dis 2004; 39 Suppl 2: S132-S139

12. Boulton AJ, Vileikyte L, Ragnarson-Tennvall G, Apelqvist J. The global burden of diabetic foot disease. Lancet 2005; 366: 1719-1724

13. Byford S, Torgerson DJ, Raftery J. Cost of illness studies. BMJ. 2000;320(7245): 1335.

14. Yazdanpanah Leila, Nasiri Morteza, Adarvishi Sara. Literature review on the management of diabetic foot ulcer. World J Diabetes .2015. 15; 6(1): 37-53.

15. Charmaine. Mathiass.Cost-of-illness studies of diabetes mellitus: A systematic review Diabetes research and clinical practice.2015.151-163 .

16. Alexiadou Kleopatra, Doupis John. Management of Diabetic Foot Ulcers. Diabetes Ther 2012. 3:4.

17. Kim Tae Gyun.Moon Sang Young . Factors Affecting Length of Hospital Stay and Mortality in Infected Diabetic Foot Ulcers Undergoing Surgical Drainage without Major Amputation. J Korean Med Sci 2016; 31: 120-124

18. Keskek SO, Kirim S, Yanmaz N. Estimated costs of the treatment of diabetic foot ulcers in a tertiary hospital in Turkey. Pak J Med Sci 2014;30 (5):968-971.

19. Cichero Matthew J, Bower2 Virginia M Reducing length of stay for acute diabetic foot episodes: employing an extended scope of practice podiatric high-risk foot coordinator in an acute foundation trust hospital. Journal of Foot and Ankle Research 2013, 6:47

20. Yesudian Charles AK, Grepstad Mari, Visintin Erica and Alessandra FerrarioThe economic burden of diabetes in India: a review of the literature. Globalization and Health 2014, 10:80

21. Alexiadou Kleopatra Alexiadou - Doupis John Management of Diabetic Foot Ulcers. Diabetes Ther .2012. 3:4

22. Toscano Cristiana M. Sugita Tatiana H. Annual Direct Medical Costs of Diabetic Foot Disease in Brazil: A Cost of Illness Study. Int. J. Environ. Res. Public Health 2018, 15: 89 
23. Charmaine S,Joyce, Matthias . Cost-of-illness studies of diabetes mellitus: A systematic review. Diabetes research and clinical practice 105. 2014:151-163 